\title{
NEW RESULTS ON $\alpha$-SPECTRAL RADIUS OF GRAPHS
}

\author{
HONGYING LIN AND BO ZHOU*
}

\begin{abstract}
For $0 \leqslant \alpha<1$, Nikiforov proposed to study the spectral properties of the family of matrices $A_{\alpha}(G)=\alpha D(G)+(1-\alpha) A(G)$ of a graph $G$, where $D(G)$ is the degree diagonal matrix and $A(G)$ is the adjacency matrix. The $\alpha$-spectral radius of $G$ is the largest eigenvalue of $A_{\alpha}(G)$. For $0 \leqslant \alpha<1$, we give a lower bound for the $\alpha$-spectral radius, and bounds for the maximum and minimum entries of the $\alpha$-Perron vector, and we determine the unique graph with maximum $\alpha$-spectral radius among graphs with given number of odd vertices.
\end{abstract}

Mathematics subject classification (2020): 05C50, 15A18.

Keywords and phrases: $\alpha$-spectral radius, $\alpha$-Perron vector, graph, odd vertices, maximum degree.

\section{REFERENCES}

[1] S. M. CiOAB Ă AND D. A. GRegory, Large matchings from eigenvalues, Linear Algebra Appl. 422, 1 (2007), 308-317.

[2] S. M. CIOAB Ă AND D. A. GREGORY, Principal eigenvectors of irregular graphs, Electron. J. Linear Algebra 16, (2007), 366-379.

[3] D. CVetKović And P. Rowlinson, The largest eigenvalue of a graph: a survey, Linear Multilinear Algebra 28, 1-2 (1990), 3-33.

[4] D. Cvetrović, P. Rowlinson And S. K. Simić, Signless Laplacians of finite graphs, Linear Algebra Appl. 423, 1 (2007), 155-171.

[5] H. Guo AND B. ZHou, On the $\alpha$-spectral radius of graphs, Appl. Anal. Discrete Math. 14, 2 (2020), $431-458$.

[6] H. Minc, Nonnegative Matrices, John Wiley \& Sons, New York, 1988.

[7] V. NiKIFOROV, Bounds on graph eigenvalues II, Linear Algebra Appl. 427, 2-3 (2007), 183-189.

[8] V. Nikiforov, Merging the A- and Q-spectral theories, Appl. Anal. Discrete Math. 11, 1 (2017), $81-107$.

[9] V. Nikiforov And O. Rojo, On the $\alpha$-index of graphs with pendent paths, Linear Algebra Appl. 550, (2018), 87-104.

[10] V. Nikiforov, A spectral condition for odd cycles in graphs, Linear Algebra Appl. 428, 7 (2008), 1492-1498.

[11] S. K. Simić And B. Zhou, Indices of trees with a prescribed diameter, Appl. Anal. Discrete Math. 1, 2 (2007), 446-454.

[12] R. XING AND B. ZHou, Laplacian and signless Laplacian spectral radii of graphs with fixed domination number, Math. Nachr. 288, 4 (2015), 476-480.

[13] B. ZHOU, Signless Laplacian spectral radius and Hamiltonicity, Linear Algebra Appl. 432, 2-3 (2010), 566-570. 